July - 2005

\title{
Book Review - Learner Support in Open, Distance and Online Learning Environments
}

Editors: J. Brindley, C. Walti, and O. Zawacki-Richter (2004). Learner Support in Open, Distance and Online Learning Environments. Bibliotheks - und Informationssystem der Universitat Oldenburg. ISBN: 3814209230

Reviewed by: Stacey Ludwig, Director of Academic Services, Western Governors University, USA.

There is a growing need for high quality, proactive, learner-centered support services for distance learning students. Learner-Support in Open, Distance and Online Learning Environments is the ninth volume in the ASF series on distance education that specifically addresses learner support systems. The text provides an introduction to the current literature encompassing learner support services, as well as a useful introduction to the trends and issues facing learner support practitioners, and implementation and evaluation of practices.

Learner-Support in Open, Distance and Online Learning Environments has 25 contributors providing thoughtful reflection and analyses of the major challenges facing learner support practitioners such as scaling to meet growing student populations, scarce resources, immense technological changes, and greater emphases on learner-centered yet institutionally-connected services. The text is comprised of four sections or units. Unit one focuses on visions and retrospectives. The contributors to unit one provide detailed literature reviews, historical perspectives, and thoughtful reflection on the complexities of providing support services to distance learners. We are reminded that distance learning is more than just a business and that the roles of faculty, students, administrators, and learner support practitioners must change to retain and meet the needs of distance learners. The contributors also address pedagogical issues related to e-learning and the development of courses that are both flexible and collaborative. Unit one is an excellent introduction to the literature relating to learner support systems.

Unit two of Learner-Support in Open, Distance and Online Learning Environments focuses on strategies for learner success. The contributors to unit two challenge the traditional notions of learner support by offering rationale for online learner support services, the librarian's role in developing information literacy and critical thinking skills, the use of e-portfolios and learning journals, and the development of learning communities to support the students' connection to the education provider. Unit two contributors also address gender and cultural diversity issues relating to DL environments.

Unit three of Learner-Support in Open, Distance and Online Learning Environments focuses on the planning and management of learner support systems. The contributors in unit three introduce complex issues relating to the human resource, systems, training, and project management practices related to designing and implementing learner support services. Unit three also includes in-depth discussions about the quality, effectiveness, efficiency, and flexibility of learner support systems and how to develop research and evaluation systems to measure outcomes. Unit three is a 
series of chapters aimed at the more advanced practitioner that encourage the reader to explore the concepts in more detail beyond the scope of the text. Readers get enough information from the text to begin formulating research and evaluation questions related to measuring cost effectiveness and quality of learner support systems.

Unit four of Learner-Support in Open, Distance and Online Learning Environments includes three keynote addresses from the 2004 EDEN Conference on Learner Support. A DVD accompanies the text which includes the original recordings of the keynote speeches by Terry Anderson, Nicholas Allen, and Alan Tait, as well as speeches by Otto Peters, Gilly Salmon, and Elsebeth Korsgaard Soerensen.

Overall, I enjoyed the text. The units and chapters are weaved together nicely so that the reader flows from one chapter to the next. Again, I would recommend this text to practitioners that are new to distance learning because it provides an overview of the literature as well as an introduction to the trends and issues. More experienced practitioners will benefit from the review of the recent literature in learner support services, as well as the units covering implementation, research, and evaluation of learner support practices.

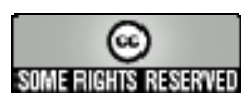

